J. Gastroenterol. Hepatol. Erkr. 2019 · 17:93 https://doi.org/10.1007/s41971-019-00065-2

(c) Springer-Verlag GmbH Austria, ein Teil von Springer Nature 2019

\title{
Editorial
}

\section{Liebe Kollegen!}

Im letzten Heft des Jahres 2019 berichtet das Journal für Gastroenterologische und Hepatologische Erkrankungen in einer sehr schön geschriebenen Übersicht von Prof. Oberhuber über die pathologischen Standards in der Befundung von Pancreas-Präparaten. Dieses Thema ist durch die zunehmende Inzidenz von Pancreastumoren und den zunehmenden Einsatz der endosonographischen Biopsie bei deren Abklärung überfällig.

Ebenfalls mit dem Pancreas beschäftigt sich der Beitrag über die medikamentös-induzierte Pancreatitis der Kollegen Wurm und Spindelböck aus Graz. Auch wenn wir häufiger mit medikamentösinduzierten Hepatopathien konfrontiert sind, so dürfen wir bei Pancreasaffektionen nicht vergessen, dass diese ebenso medikamentös induziert sein können.

Außerdem freuen wir uns, das Expertenstatement zur österreichischen Perspektive für das interdisziplinäre Management von immun-mediierten Erkrankungen präsentieren zu dürfen, welches von namhaften Kollegen aus dem Bereich der Gastroenterologie in Kooperation mit Neurologen, Ophthalmologen, Dermatologen und Rheumatologen erstellt wurde.

Ich hoffe, wir konnten auch diesmal wieder interessante Beiträge für Sie zusammenstellen, und verbleibe mit kollegialen Grüßen, Ihr

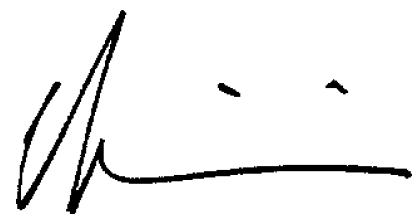

Prim. Univ.-Prof. Dr. Markus Peck-Radosavljevic

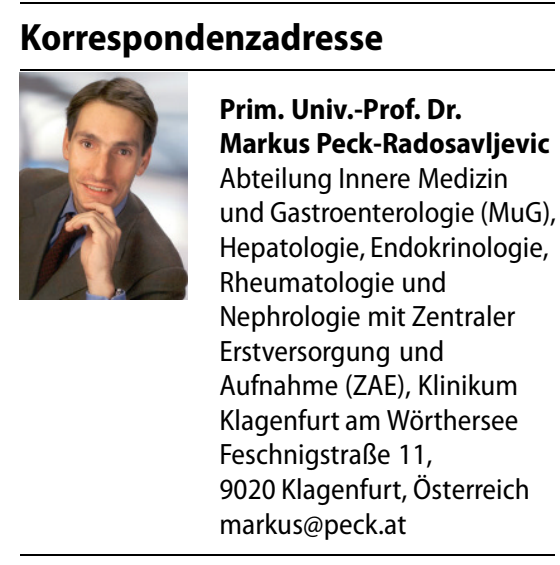

Interessenkonflikt. M. Peck-Radosavljevic gibt an, dass kein Interessenkonflikt besteht.

Hinweis des Verlags. Der Verlag bleibt in Hinblick auf geografische Zuordnungen und Gebietsbezeichnungen in veröffentlichten Karten und Institutsadressen neutral. 